\title{
Mitral Valvular Interstitial Cells Demonstrate Regional, Adhesional, and Synthetic Heterogeneity
}

\author{
Tracy L. Blevins ${ }^{a}$ Sherket B. Peterson ${ }^{a} \quad E^{2}$ laine L. Lee ${ }^{b} \quad$ Annie M. Bailey ${ }^{c}$ \\ Jonathan D. Frederick ${ }^{d}$ Thanh N. Huynh ${ }^{\text {a }}$ Vishal Gupta ${ }^{a} \quad$ K. Jane Grande-Allen ${ }^{a}$ \\ ${ }^{a}$ Department of Bioengineering, Rice University, Houston, Tex., ${ }^{b}$ Department of Biomedical Engineering, \\ Case Western Reserve University, Cleveland, Ohio, 'Department of Biology, Howard University, \\ Washington, D.C., and d Department of Engineering and Physics, Murray State University, Murray, Ky., USA
}

\section{Key Words}

Valvular interstitial cells · Adhesion · Cardiovascular system - Cell-cell interactions - Cell-matrix interactions · Collagen • Glycosaminoglycans • Heart valves •

Mechanobiology

\section{Abstract}

Background/Aims: Because various regions of the mitral valve contain distinctive extracellular matrix enabling the tissues to withstand diverse mechanical environments, we investigated phenotype and matrix production of porcine valvular interstitial cells (VICs) from different regions. Methods: VICs were isolated from the chordae (MCh), the center of the anterior leaflet (AICtr), and the posterior leaflet free edge (PIFree), then assayed for metabolic, growth, and adhesion rates; collagen and glycosaminoglycan (GAG) production, and phenotype using biochemical assays, flow cytometry, and immunocytochemistry. Results: The AICtr VICs exhibited the fastest metabolism but slowest growth. PIFree cells grew the fastest, but demonstrated the least smooth muscle $\alpha$-actin, vimentin, and internal complexity. AICtr VICs secreted less collagen into the culture medium but more 4sulfated GAGs than other cells. Adhesion-based separation resulted in altered secretion of sulfated GAGs by MCh and AICtr cells but not by the PIFree cells. Conclusions: VICs isolated from various regions of the mitral valve demonstrate phenotypic differences in culture, corresponding to the ability of the mitral valve to accommodate the physical stresses or altered hemodynamics that occur with injury or disease. Further understanding of VIC and valve mechanobiology could lead to novel medical or tissue engineering approaches to treat valve diseases.

Copyright $\odot 2007$ S. Karger AG, Basel

\section{Abbreviations used in this paper}

AlCtr center of the anterior leaflet

ANOVA analysis of variance

BGS bovine growth serum

GAGs glycosaminoglycans

MCh mitral chordae

MTT 3-(4,5-dimethylthiazol-2-yl)-2,5-diphenyl tetrazolium bromide

PlFree posterior leaflet free edge

$\mathrm{SM} \alpha \mathrm{A} \quad$ smooth muscle $\alpha$-actin

VICs valvular interstitial cells

\section{KARGER}

๑ 2007 S. Karger AG, Basel

Fax +41613061234

E-Mail karger@karger.ch

www.karger.com
Accessible online at: www.karger.com/cto
Dr. K. Jane Grande-Allen

Department of Bioengineering, Rice University

6100 Main Street, MS-142

Houston, TX 77005 (USA)

Tel. +1 713348 3704, Fax +1 713348 5877, E-Mail grande@rice.edu 


\section{Introduction}

The mitral valve is anatomically complex with various regions of the tissue experiencing different mechanical loads [Kunzelman et al., 1993, 1994]. Numerous previous studies have shown that the extracellular matrix composition of different regions of the mitral valve is well suited to withstand the unique mechanical demands upon that region [McDonald et al., 2002; Grande-Allen et al., 2003, 2004, 2005]. For example, mitral chordae, which experience high cyclic tensile loading, contain abundant collagen and the small leucine-rich proteoglycans decorin and biglycan, which regulate collagen fibrillogenesis. The central 'clear zone' of the anterior leaflet, which is continuous with the subaortic curtain beneath the left and noncoronary aortic valve leaflets, is exposed to membrane-like tension as it distends to obstruct the mitral orifice. This central region of the anterior leaflet predominantly consists of circumferentially aligned collagen and has a significantly higher elastic modulus than the free edges of the anterior and posterior leaflets [Kunzelman and Cochran, 1992]. These leaflet free edges appose each other during valve closure, and correspondingly are rich in the glycosaminoglycan (GAG) hyaluronan and the proteoglycan versican, which provide resistance to compression. The heterogeneous makeup, material behavior, and mechanical loading of the different mitral valve regions likely provide both endogenous [Discher et al., 2005] and exogenous mechanical stimulation to the valvular interstitial cells (VICs) that may be reflected in their phenotype. Indeed, the relationship between the mechanical stimulation experienced by the tissues and the resultant loading and deformation local to the VICs may be highly non-linear and dependent upon the coupling of the pericellular collagen and elastin to the cell as well as the small-scale kinematics of these fibers.

VICs from multiple species demonstrate heterogeneous phenotypic morphology and staining for smooth muscle $\alpha$-actin $(\mathrm{SM} \alpha \mathrm{A})$ in two- and three-dimensional culture [Messier et al., 1994; Taylor et al., 2000, 2002; Durbin and Gotlieb, 2002; Butcher and Nerem, 2004] and in immunohistochemistry of valve sections [Taylor et al., 2000; Rabkin et al., 2002]. It has been suggested that VICs expressing high levels of $\mathrm{SM} \alpha \mathrm{A}$ are metabolically active and are responsible for the development and repair of valve tissues [Durbin and Gotlieb, 2002] and the contractile nature of valves [Cimini et al., 2003]. Recently, it was demonstrated that VICs from the left-sided heart valves (mitral and aortic), which are subjected to higher transvalvular pressures, contain more $\mathrm{SM} \alpha \mathrm{A}$ and heat shock protein 47 (a molecular chaperone involved in collagen synthesis) and have greater cellular stiffness than the right-sided heart valves [Merryman et al., 2006]. Moreover, the stiffness of the substrate on which VICs are grown has been shown to affect the cell phenotype, in that VICs grown on rigid plastic were more spread and expressed more $\mathrm{SM} \alpha \mathrm{A}$ than those grown on flexible polyacrylamide [Throm et al., 2005]. We have previously shown that VIC heterogeneity in terms of adherence to tissue culture plastic can be the basis for the separation of VICs into distinct subpopulations [Blevins et al., 2006]. However, we speculated that VICs also vary regionally, i.e. cells from distinct regions of the mitral valve exhibit functional differences corresponding to their varied pericellular and mechanical environments, as described above. Therefore, we have analyzed the cell phenotype of VICs grown from three different regions of the porcine mitral valve that experience different mechanical forces during the cardiac cycle. Characteristics investigated included metabolic, growth, and adhesion rates, and expression of the cytoskeletal components $\mathrm{SM} \alpha \mathrm{A}$ and vimentin. The differential expression of $\alpha_{2} \beta_{1}$ integrins was also assessed since the $\beta_{1}$ class was recently found to be the predominant type of integrins in VICs [Latif et al., 2005b]. Finally, the secretion of GAGs and collagen were measured. Phenotypic differences between the VICs in these various anatomic regions are relevant to an understanding of normal valve function and mechanobiology and therefore to the design of tissue-engineered heart valves [Flanagan et al., 2006].

\section{Materials and Methods}

Mitral Valve Regional Dissection and Primary Culture

Porcine hearts from healthy 6-month-old pigs were purchased over several months from Fisher Ham and Meats, Spring Cypress, Tex., USA; valves from several porcine hearts were pooled together each of 6 times the cells were harvested for primary culture (between 3-12 hearts per cell harvest). Porcine heart valves have been widely used as a model for anatomic [Kunzelman et al., 1994] and cell biological [Walker et al., 2004; Cushing et al., 2005] aspects of human heart valves. After visual inspection to ensure normal leaflet and chordal anatomy [Kunzelman et al., 1994], tissues were dissected from three specific regions (anterior leaflet center 'AlCtr', mitral chordae 'MCh' and posterior leaflet free edge 'PlFree'; fig. 1). These tissues were placed in a collagenase II solution $(2 \mathrm{mg} / \mathrm{ml}$ collagenase II in serum-free Dulbecco's modified Eagle's medium with $1 \%$ antibiotic/antimycotic/antifungal solution; culture solutions purchased from Mediatech, Herndon, Va., USA; all enzymes from Worthington Biochemical, Worthington, Va., USA) and incubated in a shaker for $20 \mathrm{~min}\left(37^{\circ} \mathrm{C}, 140\right.$ $\mathrm{rpm})$. After this treatment, the valve surfaces were brushed with 
a sterile cotton swab to remove the loosened endothelial cells; it has been shown previously in the authors' laboratory that this treatment removes endothelial cells (the final cell population does not stain for CD31 [Blevins et al., 2006]).The regional valve tissues were then minced and dissociated using $10-20 \mathrm{ml}$ of a collagenase III and hyaluronidase solution ( 1 and $0.1 \mathrm{mg} / \mathrm{ml}$ in medium, respectively) for $4 \mathrm{~h}\left(37^{\circ} \mathrm{C}, 140 \mathrm{rpm}\right)$. The resulting regional VIC populations were counted, seeded in tissue culture flasks at a density of 10,000 cells $/ \mathrm{cm}^{2}$ and maintained at $37^{\circ} \mathrm{C}, 95 \%$ humidity, and $5 \% \mathrm{CO}_{2}$. Cells were passaged after reaching $70 \%$ confluence and experimentally tested at passages $2-3$. During primary culture and in all of the following experiments, cells were grown on standard tissue culture plastic dishes (except for immunocytochemistry) and maintained in Dulbecco's modified Eagle's medium containing $10 \%$ bovine growth serum (HyClone, Logan, Utah, USA) and 1\% antibiotic/antimycotic/antifungal solution.

\section{Metabolism, Adhesion, and Growth Analysis}

The metabolic rates of the regional VICs were assessed by the addition of 3-(4,5-dimethylthiazol-2-yl)-2,5-diphenyltetrazolium bromide (MTT, Sigma, St. Louis, Mo., USA). Ten, 50, 100 or $200 \times 10^{3}$ cells were added to wells of a 12 -well plate (surface area $3.8 \mathrm{~cm}^{2} /$ well), returned to the tissue culture incubator, and immediately subjected to an MTT assay. Each well received an aliquot of MTT reagent (100 $\mu \mathrm{l}$ of $5 \mathrm{mg} / \mathrm{ml}$ in sterile PBS) prior to $4 \mathrm{~h}$ of incubation $\left(37^{\circ} \mathrm{C}\right)$, was then treated with $1 \mathrm{ml} \mathrm{MTT}$ solvent $(0.1 \mathrm{~N} \mathrm{HCl}$ in isopropanol), and the resulting solutions were triturated until the formazan blue crystals dissolved. The net absorbance $\left(\mathrm{A}_{690}-\mathrm{A}_{570}\right)$ of the solution was measured in triplicate to determine the cellular rates of MTT metabolism. The relationship between cell number and MTT metabolic rate was determined by linear regression for each regional VIC group and then used to calculate cell numbers for the subsequent growth studies.

For the adhesion analysis, $5 \times 10^{4}$ regional VICs were added to duplicate wells of a 12-well plate. After 1, 10, 30, 120, and 240 min, the culture medium (containing any unattached cells) was aspirated, the specific wells were washed with $1 \mathrm{ml}$ of medium, and the adherent cells were counted in triplicate using the MTT assay. To determine the MTT value that would result from total cell adhesion, an additional set of duplicate wells was seeded with $5 \times 10^{4}$ regional VICs, incubated for $240 \mathrm{~min}$, and subjected to the MTT assay without washing away unadherent cells.

For the growth study, $5 \times 10^{4}$ regional VICs were added to duplicate wells of a 12-well plate in $1 \mathrm{ml}$ of culture medium, and the MTT assay was performed in triplicate on days $0,1,2,3,5$, and 7. A duplicate set of growth experiments was performed using trypan blue exclusion to count the cells.

\section{Flow Cytometry}

Antibody labeling and flow cytometry was performed as previously described [Blevins et al., 2006]. Briefly, regional VICs grown to $70 \%$ confluence were trypsinized, fixed with $1 \%$ paraformaldehyde, permeabilized with $1 \%$ Triton X-100 (Roche Diagnostics, Indianapolis, Ind., USA), and then divided equally into replicate volumes. Rinsed, pelleted cells were labeled with $100 \mu \mathrm{l}$ of flow cytometry buffer (0.5\% BSA, $0.05 \%$ sodium azide in PBS) containing primary antibodies. The antibodies used were anti$\mathrm{SM} \alpha \mathrm{A}$, anti-vimentin (both from Dako, Glostrup, Denmark), anti- $\alpha_{2} \beta_{1}$ integrin (Chemicon, Temecula, Calif., USA), anti-collagen I (Novus Biologicals, Littleton, Colo., USA), and anti-col-

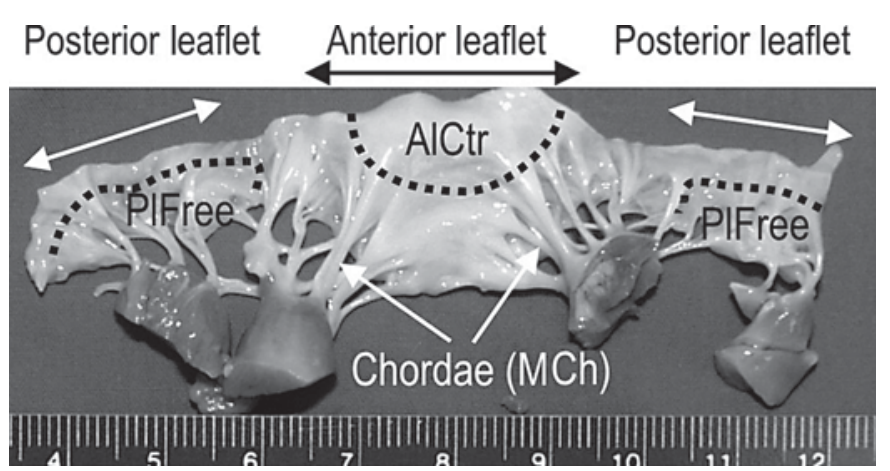

Fig. 1. Mitral valve cut open to show ventricular aspect. Dotted lines and arrows denote the regions from which the three cell types were derived.

lagen III (AbCam, Cambridge, Mass., USA); all primary antibodies were diluted 1:100 for all experiments, except for vimentin (1:200). After washing, the cell samples were incubated with 100 $\mu l$ of the secondary antibody (goat anti-mouse and anti-rabbit IgG FITC, Jackson ImmunoResearch, West Grove, Pa., USA) diluted 1:200 in flow-cytometric buffer. The samples were then washed and resuspended in $1 \mathrm{ml}$ buffer. Median fluorescence and side scatter intensities were determined in triplicate for 10,000 cells for each sample by a FACSCan (BD Biosciences, San Jose, Calif., USA) and compared to control VICs that were only labeled with the secondary antibody. VICs grown from a fetal porcine valve (Animal Technologies, Tyler, Tex., USA) were used as an additional comparison and as a positive control for $\mathrm{SM} \alpha \mathrm{A}$, since fetal human valves are reported to express very high amounts of this cytoskeletal marker [Rabkin-Aikawa et al., 2004]. To compare between different flow-cytometric runs, the side scatter intensities of the PlFree and AlCtr cells from each antibody labeling preparation were normalized to the MCh intensities.

\section{Immunocytochemistry}

Cells were seeded at $5 \times 10^{3}$ cells $/ \mathrm{cm}^{2}$ on glass microscope slides and maintained in complete culture medium in a tissue culture incubator. After 2 days (approximately 70\% confluence), the cells were rinsed with PBS, then fixed by two 10 -min incubations in $100 \%$ acetone at room temperature. The cells were incubated with the same primary and secondary antibodies (at identical dilutions, in PBS containing 1\% bovine serum albumin and $0.1 \%$ Triton X-100) as used in flow cytometry. Negative controls were prepared without primary antibodies. The slides were washed three times with PBS, drained, mounted with Vectashield with DAPI (Vector Laboratories, Burlingame, Calif., USA), coverslipped, and sealed. The slides were imaged using the $\times 10 \mathrm{ob}-$ jective of an Axioplan fluorescent microscope (Zeiss, Thornwood, N.Y., USA). Three images were taken from non-overlapping, randomly chosen regions of each slide. The total number of cells in each image was counted using the DAPI nucleic acid marker, and the cells that stained with the green FITC were counted and categorized as either stained or intensely stained $(>5 \times$ intensity of other stained cells). The slides were scored as either negative $(-),<5 \%$ positive cells $( \pm), 5-10 \%$ positive $(+), 10-50 \%$ positive $(++)$, or $>50 \%$ positive $(+++)$. Several (3-9) images of cells 
categorized as staining ++ or +++ were analyzed using MetaMorph software (Molecular Devices, Downingtown, Pa., USA) to quantify the fluorescence intensity of the FITC-stained marker in relation to the number of DAPI-stained cell nuclei.

\section{Secretion of GAGs and Collagen}

Fluorophore-assisted carbohydrate electrophoresis was used to measure GAGs secreted into the culture medium by the VICs in two separate analyses. The first analysis was performed on undivided groups of the regional cells, whereas the second analysis was performed after the cell groups had been subdivided using differential adhesion, since that method has been shown to result in distinct subpopulations of VICs previously [Blevins et al., 2006]. In the 'undivided' analysis, regional VIC cultures were established with $7.5 \times 10^{5}$ cells/T75 flask in $8 \mathrm{ml}$ of complete medium; three flasks were prepared for each VIC group. After 4 days, the 9 conditioned medium samples and one equivalent volume of fresh medium were each incubated with $0.4 \mathrm{mg}$ proteinase $\mathrm{K}$ (Invitrogen, Carlsbad, Calif., USA) at $60^{\circ} \mathrm{C}$ for $2 \mathrm{~h}$, then $30 \mathrm{~min}$ at $>70^{\circ} \mathrm{C}$ to denature the enzyme. An $0.8-\mathrm{ml}$ aliquot of each conditioned and fresh medium sample was diluted $1: 1$ with $1 \%$ Triton $\mathrm{X}-100$ before batch purification using ion exchange and ethanol precipitation as previously described [Gupta et al., 2007]. The precipitated GAG chains were rehydrated in $0.1 \mathrm{M} \mathrm{NH}_{4}$ acetate and enzymatically cleaved into disaccharides by chondroitinases $\mathrm{ABC}$ and ACII ( $3 \mathrm{mU}$ each, Associates of Cape Cod, Falmouth, Mass., USA) for $3 \mathrm{~h}$ at $37^{\circ} \mathrm{C}$. The resulting disaccharides were vacuum dried and then fluorescently labeled with 2-aminoacridone $\mathrm{HCl}$ (Molecular Probes, Eugene, Oreg., USA) in a final volume of $100 \mu \mathrm{l}$, as previously described [Grande-Allen et al., 2004]. Aliquots $(5 \mu \mathrm{l})$ were electrophoresed at a constant voltage of $500 \mathrm{~V}$ in ice-cold TBE buffer $(0.89 \mathrm{M}$ Tris, $0.89 \mathrm{M}$ boric acid, and $0.032 \mathrm{M}$ EDTA) for 45-60 min and then imaged under UV light. The integrated optical densities of digitally captured bands were converted to amounts of GAGs by comparison with a standard curve containing known quantities of fluorescently labeled maltotriose [Grande-Allen et al., 2004]. After the amounts of GAGs in the fresh medium were subtracted from the samples, the amounts were normalized to the original starting volume of conditioned medium. To obtain proportions, the concentrations of individual GAGs (hyaluronan and unsulfated, 6-sulfated, or 4-sulfated chondroitin/dermatan) and groups of GAGs (total sulfated or unsulfated GAGs) were divided by the total amount of GAGs measured per flask.

In addition to the analysis of the primary harvested regional VICs, the 'subdivided' analysis used differential adhesion to divide each VIC type into two subpopulations, as previously described [Blevins et al., 2006], resulting in a group of more adherent, slowly growing cells that strongly expresses $\mathrm{SM} \alpha \mathrm{A}$, and a group of less adherent, rapidly growing cells that minimally express SM $\alpha$ A. Because selected GAGs and proteoglycans can interfere with cell adhesion [Lemire et al., 2002], it was of interest to determine what GAGs were synthesized by the more adherent and less adherent cells. In the 'subdivided' analysis, the regional VIC cultures were seeded with $2.5 \times 10^{5}$ cells/T25 flask in $4 \mathrm{ml}$ of complete medium; 6 flasks were prepared for each VIC group. After $4 \mathrm{~h}$, the non-adherent cells were removed and transferred to a fresh T25 flask, where these 'weakly adherent' cells were allowed to adhere over the next 4 days. The 'strongly adherent' cells were also supplemented with medium and incubated for 4 days. After

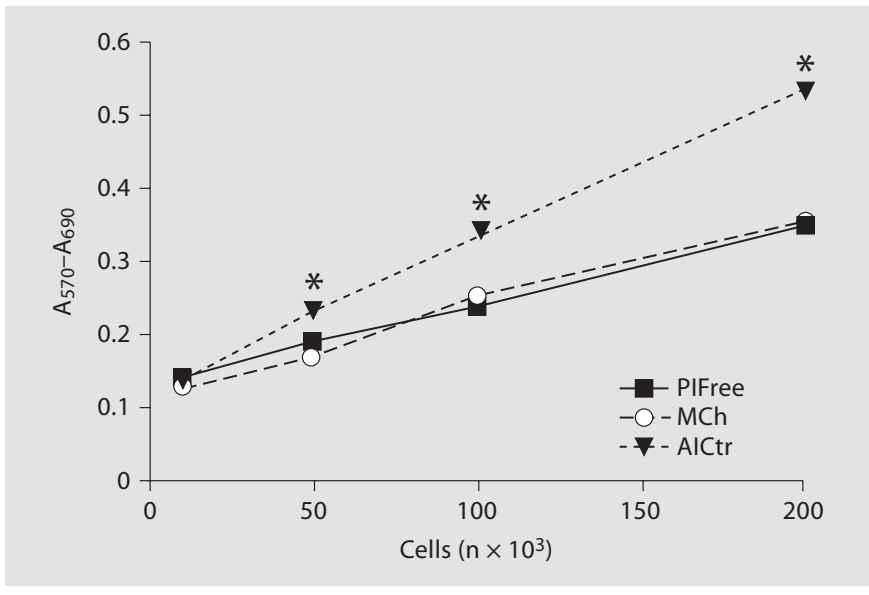

Fig. 2. MTT metabolism by regional VICs. Data points and error bars represent means $\pm \mathrm{SD}$ of triplicate MTT absorbance measurements. ${ }^{*} \mathrm{p}<0.001$, AlCtr vs. other cell types. Cell numbers: PlFree: $9.07 \times 10^{5} \cdot$ Abs $-1.19 \times 10^{5}, \mathrm{r}^{2}=0.999, \mathrm{p}<0.001$; MCh: $8.13 \times 10^{5} \cdot$ Abs $-9.38 \times 10^{4}, \mathrm{r}^{2}=0.987, \mathrm{p}=0.006$; AlCtr: $4.78 \times$ $10^{5} \cdot$ Abs $-5.99 \times 10^{4}, \mathrm{r}^{2}=0.995, \mathrm{p}=0.002$. Abs $=$ Absorbance.

this time, the medium was collected from all 36 flasks and subjected to the exact same procedure as described above.

To measure synthesized collagen, undivided VIC subpopulations were seeded at $5 \times 10^{4}$ cells in triplicate wells of a 12-well plate in medium containing $10 \%$ bovine growth serum (BGS). After $24 \mathrm{~h}$, the medium was removed and replaced with $500 \mu \mathrm{l}$ medium containing $0.1 \%$ BGS for $24 \mathrm{~h}$. The collagen within the conditioned culture medium and fresh medium was then measured using the Sircol collagen assay (Biocolor, Newtownabbey, $\mathrm{UK}$ ) according to the manufacturer's instructions. Four replicate experiments were performed.

\section{Statistical Analysis}

Data were expressed as means $\pm \mathrm{SD}$. One- and two-way analysis of variance (ANOVA) with a level of significance of $\alpha=0.05$ was performed to compare the different VIC populations and time points. Post hoc tests were used to perform subgroup comparisons. Linear regressions, descriptive statistics, and ANOVA were performed using SigmaStat (Systat Software, San Jose, Calif., USA) and GraphPad Prism (San Diego, Calif., USA).

\section{Results}

\section{Metabolism, Adherence, and Growth}

AlCtr cells were found to metabolize MTT at almost twice the rate as MCh and PlFree cells ( $\mathrm{p}<0.001$ at 50, 100 , and $200 \times 10^{3}$ cells; fig. 2 ). AlCtr cells adhered to tissue culture plates more slowly than MCh or PlFree cells ( $p=0.032$; fig. 3$)$. The PlFree and MCh cells adhered with approximately the same kinetics. The AlCtr cells showed the slowest growth rate of all three cell types, as demon- 
Table 1. Phenotyping results

\begin{tabular}{|c|c|c|c|}
\hline Protein & Cell type & $\begin{array}{l}\text { Flow cytometry } \\
\text { fluorescence } \\
\text { intensity }\end{array}$ & $\begin{array}{l}\text { Immuno- } \\
\text { cyto- } \\
\text { chemistry }\end{array}$ \\
\hline \multirow[t]{4}{*}{$\mathrm{SM} \alpha \mathrm{A}$} & PlFree & $36^{* *}$ & ++ \\
\hline & $\mathrm{MCh}$ & 95 & ++ \\
\hline & AlCtr & 106 & ++ \\
\hline & fetal & 216 & +++ \\
\hline \multirow[t]{4}{*}{ Vimentin } & PlFree & $261^{* *}$ & +++ \\
\hline & $\mathrm{MCh}$ & 381 & +++ \\
\hline & AlCtr & 380 & +++ \\
\hline & fetal & 270 & +++ \\
\hline \multirow[t]{4}{*}{$\alpha_{2} \beta_{1}$ integrin } & PlFree & $7.9^{*}$ & \pm \\
\hline & $\mathrm{MCh}$ & $6.1^{*}$ & \pm \\
\hline & AlCtr & $5.2^{*}$ & \pm \\
\hline & fetal & 7.5 & \pm \\
\hline \multirow[t]{3}{*}{ Collagen I } & PlFree & $21.5^{*}$ & + \\
\hline & $\mathrm{MCh}$ & $15.9^{*}$ & + \\
\hline & AlCtr & $18.7^{*}$ & + \\
\hline \multirow[t]{3}{*}{ Collagen III } & PlFree & $6.4^{*}$ & \pm \\
\hline & $\mathrm{MCh}$ & $8.0^{*}$ & \pm \\
\hline & AlCtr & $6.6^{*}$ & \pm \\
\hline \multirow[t]{4}{*}{ Control } & PlFree & 3.4 & - \\
\hline & $\mathrm{MCh}$ & 3.7 & - \\
\hline & AlCtr & 3.7 & - \\
\hline & fetal & 4.3 & - \\
\hline
\end{tabular}

Flow-cytometric data represent the median fluorescence intensities recorded following measurements of each antibody-labeled sample of AlCtr, MCh, and PlFree cells. Immunocytochemistry slides were scored as negative $(-),<5 \%$ positive cells $( \pm)$, $5-10 \%$ positive $(+), 10-50 \%$ positive $(++)$ and $>50 \%$ positive $(+++) .{ }^{*} \mathrm{p}<0.05$ for all comparisons between AlCtr, $\mathrm{MCh}$, and PlFree; ${ }^{* *} \mathrm{p}<0.05$ for PlFree vs. MCh and AlCtr.

strated by both the MTT assay (fig. $4 ; \mathrm{p}<0.001$ vs. PlFree days $1-7$ and vs. MCh days $2-7, \mathrm{p}<0.01$ vs. MCh day 1 ) and the trypan blue assay (data not shown). The PlFree cells grew the fastest ( $p<0.001$ vs. MCh days $1-5)$.

\section{Immunological Characterization of Phenotype}

Flow-cytometric histograms of all three cell groups and their controls demonstrated that control and vimentin curves displayed a uniformity of cell fluorescence (fig. 5a-d). The histograms for SM $\alpha$ A, however, showed a heterogeneous spread over at least three orders of magnitude, indicating that these cells expressed a widely varying amount of $\mathrm{SM} \alpha \mathrm{A}$. Over six independent flow cytometry runs (data from one representative run is shown in table 1), the AlCtr and MCh valve cells showed the highest median staining for $\mathrm{SM} \alpha \mathrm{A}$, and PlFree cells stained the least $(\mathrm{p}<0.001)$. Fetal VICs, which were used

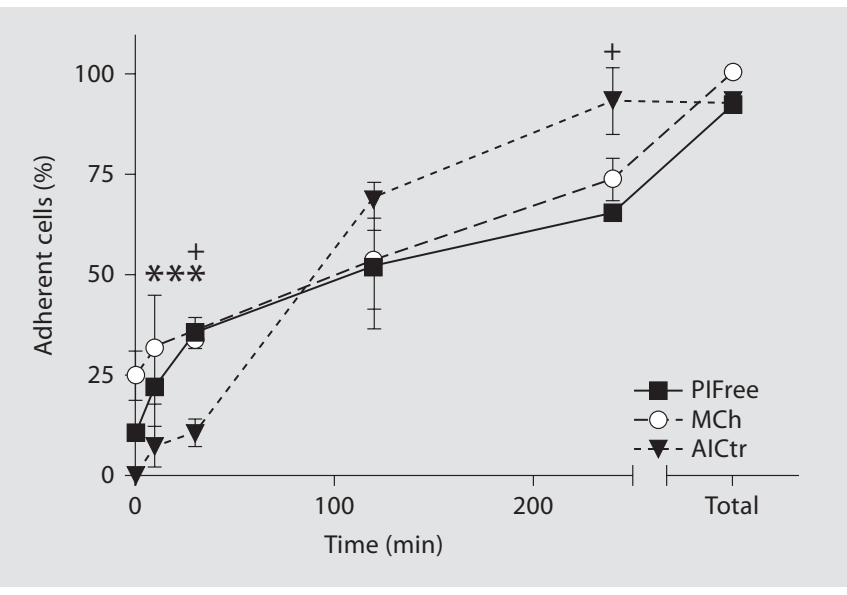

Fig. 3. Regional VIC adhesion. Data points and error bars represent means \pm SD of duplicate wells. ${ }^{*} \mathrm{p}<0.05$, AlCtr vs. MCh (at the first 3 time points); ${ }^{+} \mathrm{p}<0.05$, AlCtr vs. PlFree.

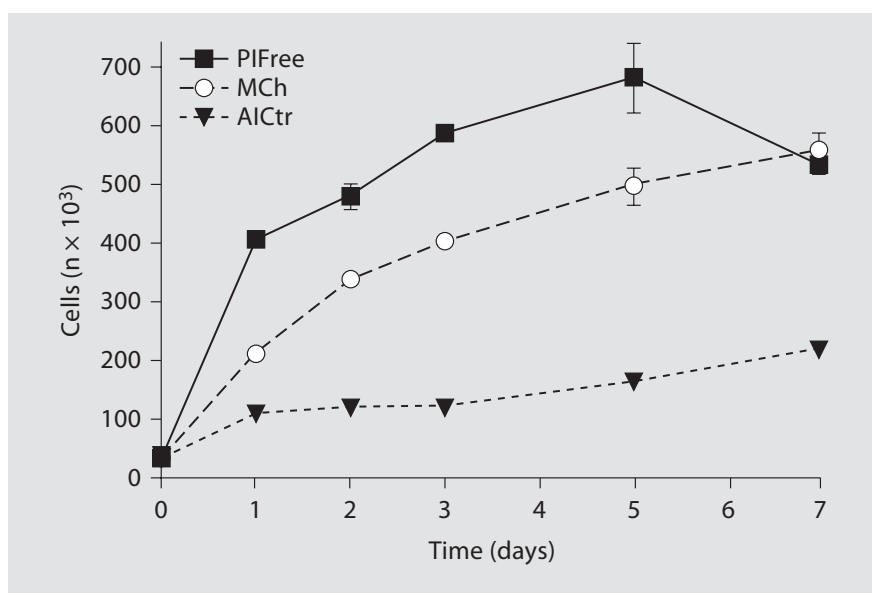

Fig. 4. Regional VIC growth. Data points and error bars represent means \pm SD of duplicate wells. Cell numbers were calculated from net absorbance using the regression equations shown in figure 2. Cell numbers were significantly different between all samples for days 1-5 and between AlCtr and the other two cell groups on day $7(\mathrm{p}<0.01)$.

as a positive control for $\mathrm{SM} \alpha \mathrm{A}$ expression [RabkinAikawa et al., 2004], demonstrated a uniformly high level of $\mathrm{SM} \alpha \mathrm{A}$, as expected. Vimentin expression was high among all VIC groups tested, as previously reported for mixed cell populations and valve histological sections [Taylor et al., 2002; Rabkin-Aikawa et al., 2004]. Even though the overall magnitude of expression of the other markers was much lower across all three VIC groups, these markers also showed differences between VIC subtypes (table 1). PlFree cells expressed the highest amount 
Fig. 5. a-d Representative histograms from fluorescence-activated flow cytometry showing expression of $\mathrm{SM} \alpha \mathrm{A}$ and vimentin by AlCtr cells (a), MCh cells (b) and PlFree cells (c) as well as fetal porcine VICs (d). The fetal VICs were used in flow cytometry as a positive control for $\mathrm{SM} \alpha \mathrm{A}$. Negative controls were not incubated with the primary antibody. e, f Representative immunocytochemical stains showing SM $\alpha \mathrm{A}$ in PlFree cells (e) and vimentin in AlCtr cells (f). Bar $=100 \mu \mathrm{m}$.
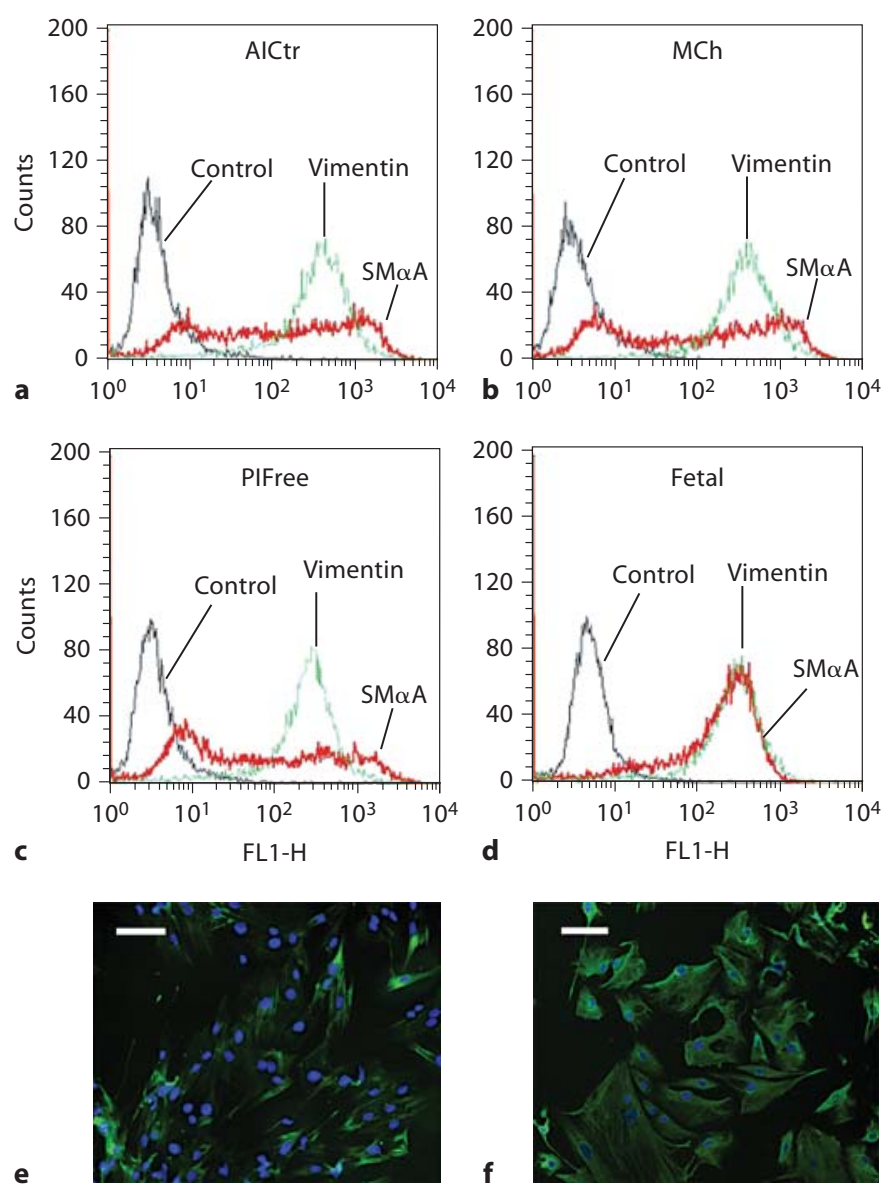

of collagen I, while the MCh cells expressed more collagen III (both $\mathrm{p}<0.001$ ); collagen I expression was almost 3 times higher than collagen III expression $(\mathrm{p}=0.002)$. $\alpha_{2} \beta_{1}$ integrin staining was highest in PlFree cells and lowest in AlCtr cells $(\mathrm{p}<0.001)$. Side scatter intensities, which correspond to internal cell complexity (changes in internal refractive index due to intracellular interfaces), were analyzed from 16 separate antibody-labeling preparations. The internal complexity was highest for the AlCtr cells, lower for the MCh cells, and lowest for the PlFree cells ( $p<0.001$; fig. 6).

Immunostaining of the regional valve cells were in close agreement with the flow-cytometric results (table 1, fig. $5 \mathrm{e}-\mathrm{f}$ ), showing that $\mathrm{SM} \alpha \mathrm{A}$ was expressed at the same low, heterogeneous levels across all three valve regions, with approximately $15-30 \%$ of positive cells staining very strongly in all three cell groups. Digital analysis of the $\mathrm{SM} \alpha \mathrm{A}$ immunostaining showed that the fluorescence intensity per cell was significantly lower for the PlFree cells $\left(\right.$ AlCtr $2.05 \pm 1.49 \times 10^{5}$, PlFree $2.22 \pm 1.21 \times 10^{4}$, MCh $2.07 \pm 0.87 \times 10^{5}$; units are intensity per cell nuclei, $\mathrm{p}<0.01)$. Almost all AlCtr, MCh, and PlFree cells stained positively for vimentin, but the proportion of strongly staining cells was lower (60\%) in the PlFree cell group than in the AlCtr and MCh groups (95-100\%). The digital images of the vimentin-stained VICs had fluorescence intensities per cell that were greater than those of the $\mathrm{SM} \alpha \mathrm{A}$ images (data not shown), but were not significantly different between groups. $\alpha_{2} \beta_{1}$ integrin and collagen type III staining was minimal in all three cell groups, but collagen type I staining was evident in $5-10 \%$ of all cells.

\section{Extracellular Matrix Secretion}

Although the three regional VIC groups secreted similar quantities of total GAGs (per ml of medium), they produced distinct proportions of selected GAG classes (fig. 7). In the 'undivided' analysis, the MCh and PlFree 

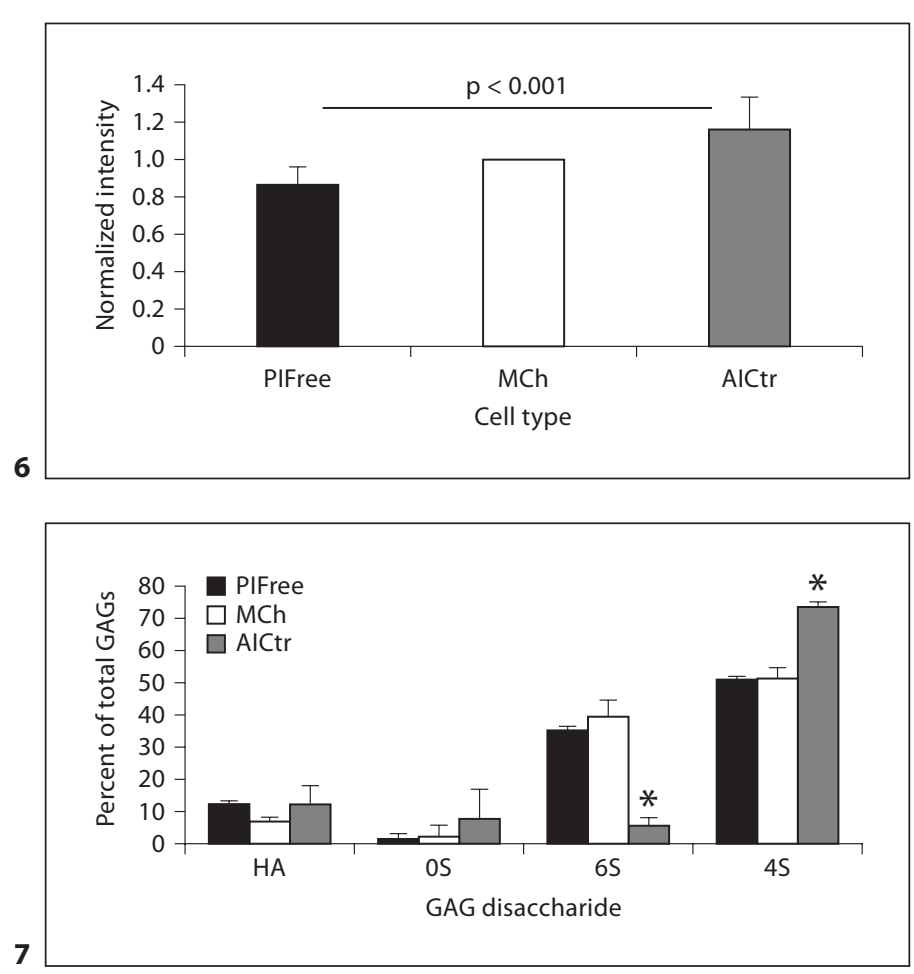

Fig. 6. Regional VIC complexity. Side scatter intensities from flow cytometry (means $\pm \mathrm{SD}$ ), which correspond to internal cell complexity, were lowest for the PlFree cells and highest for the AlCtr cells. Flow-cytometric data were normalized to the MCh values, so that the bar has a mean value of 1 and a standard deviation of 0 .

Fig. 7. GAGs secreted by regional VICs. The analysis of individual GAG disaccharides produced by regional VICs showed that AlCtr cells secreted proportionately less $6 \mathrm{~S}$ and more $4 \mathrm{~S} .{ }^{*} \mathrm{p}<$ 0.001 vs. $\mathrm{MCh}$ and PlFree. $\mathrm{HA}=$ Hyaluronan; $0 \mathrm{~S}=$ unsulfated chondroitin; $6 \mathrm{~S}=$ chondroitin/dermatan 6 -sulfate; $4 \mathrm{~S}=$ chondroitin/dermatan 4-sulfate.

Fig. 8. Ratio of sulfated to unsulfated GAGs. GAGs were assessed in regional VIC cultures that underwent adhesion-based separation to produce strongly and weakly adherent subpopulations.

cells produced comparable proportions of the different GAG classes, but the AlCtr cells secreted a lower proportion of chondroitin/dermatan 6-sulfate and a higher proportion of chondroitin/dermatan 4-sulfate (both $\mathrm{p}<$ 0.001). The proportions of hyaluronan and unsulfated chondroitin were not different between groups. In the additional analysis of the 'subdivided' subpopulations [Blevins et al., 2006] of regional VICs, the GAGs secreted by the strongly adherent AlCtr and MCh cells were significantly more sulfated than the weakly adherent AlCtr and MCh cells ( $p<0.001)$, whereas there was no difference in the ratios of sulfated to unsulfated GAGs between the two PlFree adhesion subgroups (fig. 8). MCh and
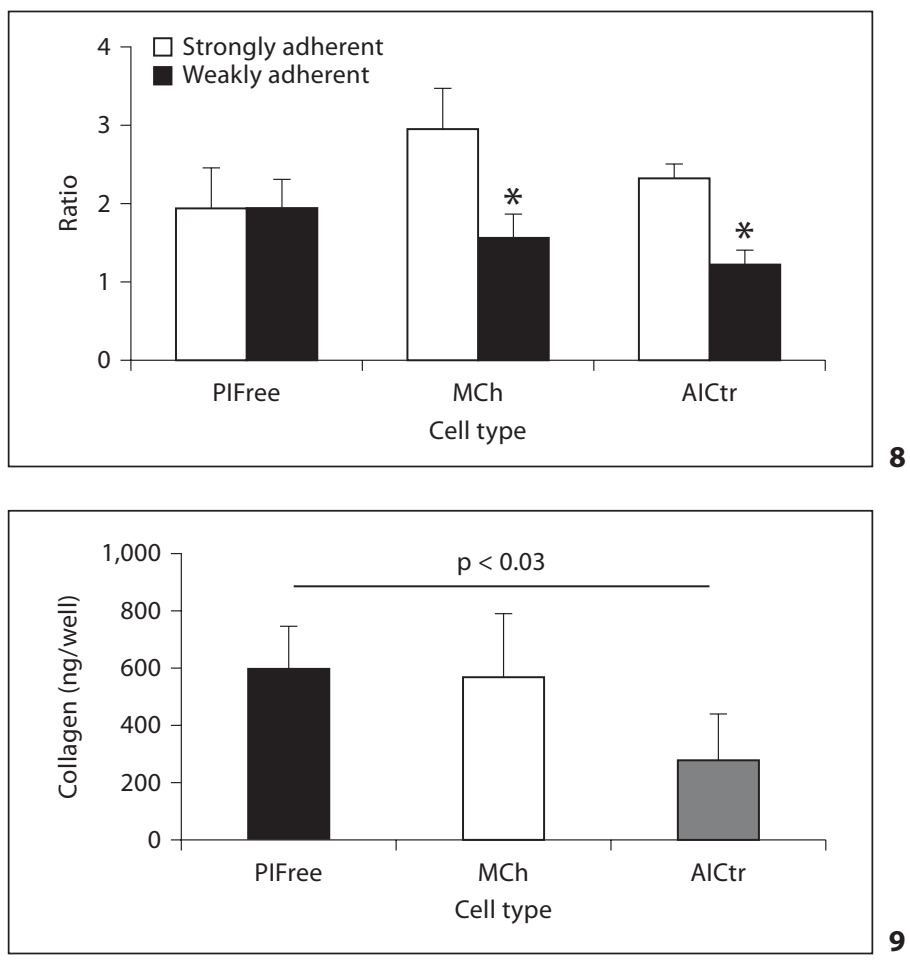

Data are presented as ratios of sulfated to unsulfated GAGs (means \pm SD of 6 flasks per group). Analysis of the different GAG disac charide classes demonstrated that the strongly adherent AlCtr and MCh cells secreted 2-3 times as many sulfated GAGs (chondroitin/dermatan 4- and 6-sulfate) as unsulfated GAGs (hyaluronan + unsulfated chondroitin). The weakly adherent AlCtr and MCh cells produced sulfated and unsulfated GAGs in more equivalent proportions (ratio closer to 1). In contrast to the AlCtr and MCh cells, the PlFree cells also secreted almost twice as many sulfated GAGs as unsulfated GAGs (ratio 2), but GAG production by the strongly adherent and weakly adherent subpopulations was almost identical. ${ }^{*} \mathrm{p}<0.001$ vs. strongly adherent cells.

Fig. 9. Regional VIC collagen synthesis. AlCtr cells secreted significantly less collagen than the PlFree cells $(\mathrm{p}<0.03)$.

PlFree cells secreted significantly more collagen into the conditioned medium than did AlCtr cells $(p<0.03$; fig. 9).

\section{Discussion}

\section{Comparison of Regional VICs}

In this study, we have provided the first demonstration that interstitial cells isolated from distinct anatomic regions of porcine mitral valves show synthetic, adhesional, and phenotypic heterogeneity. This diversity of characteristics might be due to the differences in composition 
and mechanical loading of the various valve regions. For example, there were several similar properties shared by the AlCtr and MCh cells that were different from the PlFree cells. The AlCtr and MCh cells were derived from tissues that are rich in densely packed highly aligned collagen [Kunzelman et al., 1993b], have higher elastic moduli than the leaflet free edges [Kunzelman and Cochran, 1992], and are exposed to high tensile loads [Kunzelman et al., 1993a]. These two cell groups had significantly greater internal complexity (as measured by the side scatter intensities) than the PlFree cells, which may correspond to their higher expression of $\mathrm{SM} \alpha \mathrm{A}$ and vimentin; low side-scattering intensity has also been associated with a less-differentiated cell phenotype [Budak et al., 2005]. The SM $\alpha \mathrm{A}$ content, in turn, may be indicative of the contractile nature of these tissues as well as the type and magnitude of loading that they experience [Merryman et al., 2006]. Since cells demonstrate more actin staining when they are cultured on rigid substrates [Discher et al., 2005; Throm et al., 2005], the matrix immediately surrounding the AlCtr and MCh cells (their pericellular matrix of densely packed collagen) would likely promote higher expression of cytoskeletal components. In contrast, the cells from the PlFree are derived from tissues that experience compression as opposed to tension, are rich in water-binding proteoglycans, and are less stiff [Kunzelman and Cochran, 1992], both in tension and as a substrate for cellular attachment. These characteristics would correspond to the lower internal complexity and lower expression of cytoskeletal markers in PlFree cells. In particular, the PIFree cells stained uniformly but less intensely for vimentin, as did the fetal VICs; these regions of the valve leaflets, as well as fetal valves, may not require such high cellular strength. The PlFree cells are likely very comparable to the leaflet free edge VICs that have been widely investigated by Durban and Gotlieb [2002] and recently described by Flanagan et al. [2006a]. The differential adhesion experiment revealed additional differences between the PlFree cells and the AlCtr and MCh cells. The strongly adherent PlFree cells secreted the same proportions of sulfated and unsulfated GAGs as the weakly adherent PlFree cells, suggesting that this cell population is more homogeneous in this regard than the other two groups. The greater synthesis of sulfated GAGs by the strongly adherent AlCtr and MCh cells, in contrast, is consistent with previous reports that GAG sulfation can be selectively manipulated by various types of mechanical stimulation [Merrilees et al., 1977; Sauerland et al., 2003].
In many other ways, the AlCtr cells behaved very differently from the MCh and PlFree cells. The AlCtr cells demonstrated both the highest metabolism of MTT and the highest internal complexity, perhaps due to a greater abundance of organelles [Durbin and Gotlieb, 2002; Latif et al., 2005a]. Although all cell types expressed low magnitudes of staining for $\alpha_{2} \beta_{1}$ integrins [Latif et al., 2005b], the AlCtr cells stained the least, which may explain their slower rate of adhesion. These cells also exhibited the slowest growth; an inverse relationship between $\mathrm{SM} \alpha \mathrm{A}$ expression and growth rate has been reported in dermal fibroblasts [Chipev and Simon, 2002]. Others have similarly reported an inverse relationship between the levels of $\mathrm{SM} \alpha \mathrm{A}$ and the synthesis of collagen [Lester et al., 1988; Barth et al., 2005]; the AlCtr cells secreted the least collagen of all cell types tested. In contrast to collagen secretion, the AlCtr cells secreted higher proportions of 4-sulfated disaccharides than did the MCh and PIFree cells; these GAGs tend to be found on the collagen-binding proteoglycans decorin and biglycan [Grande-Allen et al., 2004].

Despite these substantial differences in metabolism, adherence, growth, and ECM synthesis, there are similarities between these three groups. For example, all cell types expressed low levels of collagens I and III, possibly because collagen is an extracellular protein. Interestingly, the collagen I/collagen III staining intensities were approximately $3: 1$, as found in normal human valves [Lis et al., 1987]. Although the relative affinities of the different collagen antibodies may have influenced this outcome, it is important to document that both collagen isoforms were detected immunochemically since the Sircol collagen assay, which we used in our biochemical analyses, does not distinguish between isoforms. In addition, for all cell types the level of $\mathrm{SM} \alpha \mathrm{A}$ expression was low in comparison to the fetal VICs, which expressed uniform and high levels of $\mathrm{SM} \alpha \mathrm{A}$, confirming previous reports that VICs in adult valves are quiescent [Rabkin-Aikawa et al., 2004]. Furthermore, numerous phenotypic, regulatory, inflammatory, and synthetic differences between mitral-valvular endothelial cells and mitral VICs harvested from the leaflet distal edges (comparable to the PIFree cells) have been reported [Durbin and Gotlieb, 2002; Flanagan et al., 2006]. Despite the significant distinctions found between the three cell types used in this study, these cells are all likely to be even more distinct from valvular endothelial cells. It is also notable that all regional VIC populations had mixed expression of $S M \alpha A$, and the AlCtr and MCh cells demonstrated differences in GAG sulfation following adhesional separation. Mitral 
valve cells therefore demonstrate a variable phenotype both between and within anatomic regions of the valve.

Implications for Tissue Engineering and Valve Disease These phenotypic differences suggest that cells from distinct regions of the mitral valve should be used as the design goal for the development of tissue-engineered valve repair or replacement constructs for these same regions [Flanagan et al., 2006a]. For example, to tissue engineer the fibro-annular portion of the mitral valve, it may be best to utilize cells demonstrating the synthetic and contractile properties of the AlCtr cells. These desired cellphenotypic characteristics might be achieved and reinforced through a combination of mechanical or contractile conditioning and the use of scaffold materials that present the appropriate stiffness, pericellular matrix, and cell adhesion ligands [Masters et al., 2005]. This diversity would also support previously published hypotheses that subpopulations of valve cells, heterogeneously distributed either between distinct regions or throughout the valve, respond differently to the altered chemical, pharmacological, or mechanical loading conditions that are found in clinical mitral valve disease [Durbin and Gotlieb, 2002; O’Brien and Fishbein, 2005]. Culturing these cell subpopulations separately may have advantages over culturing them heterogeneously since the cells were found to have different growth rates, and slower growing cells, such as those from the AlCtr region, may form a diminishing percentage of whole VIC cultures over time as the leaflet and chordal cells proliferate more rapidly. Further characterization of these subpopulations, and extending these studies to VIC subpopulations grown from other regions of the mitral valve, will provide guideposts for the development of valve-specific medical therapies. For example, it is unknown if the basal chordae, which experience unique anchoring forces on the underside of the leaflet, contain VICs that are phenotypically different from those found within the marginal chordae. In preliminary studies, we have also subjected VICs from the free edge of the anterior leaflet to flow cytometry and found them to be similar in size and complexity to the PlFree cells. In the future, it will be important to assess how these cells respond to a variety of stimuli, such as mechanical stretch, ligation with specific growth factors or matrix-coated surfaces, or repeated passaging [Cushing et al., 2005].

\section{Study Limitations}

There are some potential limitations to this study that should be noted. It has previously been reported that after several passages, mitral VICs harvested from the anterior leaflet free edge can change from an elongated, proliferative phenotype to a more cobblestone-like, less adhesive phenotype [Durbin and Gotlieb, 2002]. Similarly, SM $\alpha$ A expression can vary with passage in culture [Cushing et al., 2005], which was a concern given that the regional VICs grew at different rates and therefore experienced different culture durations for each passage. To mitigate these effects and maintain more in situ-like characteristics, we performed our analyses on early passage VICs ( $\leq$ passage 3). We acknowledge that each cell group demonstrated some variability during culture, but the results herein represent consistent data collected from cells harvested during numerous distinct tissue dissociations. Furthermore, the cells were isolated and cultured in a consistent manner throughout the study. Another limitation is that all of these experiments were performed on VICs grown from juvenile pigs. Although heart valves from this age of pigs are widely studied as valve models [Lester et al., 1988; Walker et al., 2004; Cushing et al., 2005], a 6-month-old pig may be considered equivalent developmentally to a young adult (17-19 years old [Stephens et al., 2007]). Therefore, a continuation of this study using heart valves from much younger or much older animals (or surgically resected diseased human valves) may be more relevant to valve disease in pediatric, middle-aged, or elderly patients. Nonetheless, these data demonstrate the phenotypic heterogeneity in VICs from different mechanical environments within the normal mitral valve.

\section{Conclusion}

VICs derived from different regions of porcine mitral valves demonstrated heterogeneous behavior and expression of several phenotypic markers and extracellular matrix components, which may be due to their diverse mechanical and pericellular environments in vivo. We expect that further investigations into the heterogeneity and regulation of these characteristics should improve our understanding of the role of VICs in the biological and mechanical function of normal and diseased valves, provide design goals for tissue-engineered valves, and spur the development of novel medical therapies for valve disease.

\section{Acknowledgments}

We appreciate the assistance of Nancy Turner in the flowcytometric experiments and Alina Raza in the collagen measurements. This research was funded by the Whitaker Foundation and NIH HL081558. 


\section{References}

Barth, P.J., H. Koster, R. Moosdorf (2005) CD34+ fibrocytes in normal mitral valves and myxomatous mitral valve degeneration. Pathol Res Pract 201: 301-304.

Blevins, T.L., J.C. Carroll, A.M. Raza, K.J. Grande-Allen (2006) Phenotypic characterization of isolated valvular interstitial cell subpopulations. J Heart Valve Dis 15: 815822.

Budak, M.T., O.S. Alpdogan, M. Zhou, R.M Lavker, M.A. Akinci, J.M. Wolosin (2005) Ocular surface epithelia contain ABCG2-dependent side population cells exhibiting features associated with stem cells. J Cell Sci 118(Pt 8): 1715-1724.

Butcher, J.T., R.M. Nerem (2004) Porcine aortic valve interstitial cells in three-dimensional culture: comparison of phenotype with aortic smooth muscle cells. J Heart Valve Dis 13 478-485; discussion 485-476.

Chipev, C.C., M. Simon (2002) Phenotypic differences between dermal fibroblasts from different body sites determine their responses to tension and TGF $\beta 1$. BMC Dermatol 2: 13.

Cimini, M., K.A. Rogers, D.R. Boughner (2003) Smoothelin-positive cells in human and porcine semilunar valves. Histochem Cell Biol 120: 307-317.

Cushing, M.C., J.T. Liao, K.S. Anseth (2005) Activation of valvular interstitial cells is mediated by transforming growth factor-betal interactions with matrix molecules. Matrix Biol 24: 428-437.

Discher, D.E., P. Janmey, Y.L. Wang (2005) Tissue cells feel and respond to the stiffness of their substrate. Science 310: 1139-1143.

Durbin, A.D., A.I. Gotlieb (2002) Advances towards understanding heart valve response to injury. Cardiovasc Pathol 11: 69-77.

Flanagan, T.C., A. Black, M. O’Brien, T.J. Smith, A.S. Pandit (2006a) Reference models for mitral valve tissue engineering based on valve cell phenotype and extracellular matrix analysis. Cells Tissues Organs 183: 12-23.

-Flanagan, T.C., B. Wilkins, A. Black, S. Jockenhoevel, T.J. Smith, A.S. Pandit (2006b) A collagen-glycosaminoglycan co-culture model for heart valve tissue engineering applications. Biomaterials 27: 2233-2246.

-Grande-Allen, K.J., A. Borowski, R. Troughton, P. Houghtaling, N. DiPaola, C.S. Moravec, I. Vesely, B.P. Griffin (2005) Apparently normal mitral valves in heart failure patients demonstrate biochemical and structural derangements: an extracellular matrix and echocardiographic study. J Am Coll Cardiol 45: 54-61.

Grande-Allen, K.J., A. Calabro, V. Gupta, T.N. Wight, V.C. Hascall, I. Vesely (2004) Glycosaminoglycans and proteoglycans in normal mitral valve leaflets and chordae: association with regions of tensile and compressive loading. Glycobiology 14: 621-633.
Grande-Allen, K.J., B.P. Griffin, N.B. Ratliff, D.M. Cosgrove, I. Vesely (2003) Glycosaminoglycan profiles of myxomatous mitral leaflets and chordae parallel the severity of mechanical alterations. J Am Coll Cardiol 42: 271-277.

- Gupta, V., J.A. Werdenberg, T.L. Blevins, K.J. Grande-Allen (2007) Synthesis of glycosaminoglycans in differently loaded regions of collagen gels seeded with valvular interstitial cells. Tissue Eng 13: 41-49.

Kunzelman, K.S., R.P. Cochran (1992) Stress/ strain characteristics of porcine mitral valve tissue: parallel versus perpendicular collagen orientation. J Card Surg 7: 71-78.

Kunzelman, K.S., R.P. Cochran, C. Chuong, W. S. Ring, E.D. Verrier, R.D. Eberhart (1993a) Finite element analysis of the mitral valve. J Heart Valve Dis 2: 326-340.

Kunzelman, K.S., R.P. Cochran, S.S. Murphree, W.S. Ring, E.D. Verrier, R.C. Eberhart (1993b) Differential collagen distribution in the mitral valve and its influence on biomechanical behaviour. J Heart Valve Dis 2: 236244

Kunzelman, K.S., R.P. Cochran, E.D. Verrier R.C. Eberhart (1994) Anatomic basis for mitral valve modelling. J Heart Valve Dis 3: 491-496.

Latif, N., P. Sarathchandra, P.M. Taylor, J. Antoniw, M.H. Yacoub (2005a) Localization and pattern of expression of extracellular matrix components in human heart valves. J Heart Valve Dis 14: 218-227.

Latif, N., P. Sarathchandra, P.M. Taylor, J. Antoniw, M.H. Yacoub (2005b) Molecules mediating cell-ECM and cell-cell communication in human heart valves. Cell Biochem Biophys 43: 275-287.

Lemire, J.M., M.J. Merrilees, K.R. Braun, T.N. Wight (2002) Overexpression of the V3 variant of versican alters arterial smooth muscle cell adhesion, migration, and proliferation in vitro. J Cell Physiol 190: 38-45.

Lester, W., A. Rosenthal, B. Granton, A.I. Gotlieb (1988) Porcine mitral valve interstitial cells in culture. Lab Invest 59: 710-719.

Lis, Y., M.C. Burleigh, D.J. Parker, A.H. Child, J. Hogg, M.J. Davies (1987) Biochemical characterization of individual normal, floppy and rheumatic human mitral valves. Biochem J 244: 597-603.

Masters, K.S., D.N. Shah, L.A. Leinwand, K.S. Anseth (2005) Crosslinked hyaluronan scaffolds as a biologically active carrier for valvular interstitial cells. Biomaterials 26: 25172525.

McDonald, P.C., J.E. Wilson, S. McNeill, M. Gao, J.J. Spinelli, F. Rosenberg, H. Wiebe, B.M. McManus (2002) The challenge of defining normality for human mitral and aortic valves: geometrical and compositional analysis. Cardiovasc Pathol 11: 193-209.
Merrilees, M.J., M.A. Merrilees, P.S. Birnbaum, P.J. Scott, M.H. Flint (1977) The effect of centrifugal force on glycosaminoglycan production by aortic smooth muscle cells in culture. Atherosclerosis 27: 259-264.

Merryman, W.D., I. Youn, H.D. Lukoff, P.M. Krueger, F. Guilak, R.A. Hopkins, M.S. Sacks (2006) Correlation between heart valve interstitial cell stiffness and transvalvular pressure: implications for collagen biosynthesis. Am J Physiol Heart Circ Physiol 290: $\mathrm{H} 224-\mathrm{H} 231$.

Messier, R.H., B.L. Bass, H.M. Aly, J.L. Jones, P.W. Domkowski, R.B. Wallace, R.A. Hopkins (1994) Dual structural and functional phenotypes of the porcine aortic valve interstitial population: characteristics of the leaflet myofibroblast. J Surg Res 57: 1-21.

O'Brien, K.D., D.P. Fishbein (2005) Mitral valve abnormalities in congestive heart failure: an interplay between form and function? J Am Coll Cardiol 45: 62-64.

Rabkin-Aikawa, E., M. Farber, M. Aikawa, F.J. Schoen (2004) Dynamic and reversible changes of interstitial cell phenotype during remodeling of cardiac valves. J Heart Valve Dis 13: 841-847.

Rabkin, E., S.P. Hoerstrup, M. Aikawa, J.E. Mayer, Jr., F.J. Schoen (2002) Evolution of cell phenotype and extracellular matrix in tissue-engineered heart valves during in-vitro maturation and in-vivo remodeling. J Heart Valve Dis 11: 308-314; discussion 314.

-Sauerland, K., A.H. Plaas, R.X. Raiss, J. Steinmeyer (2003) The sulfation pattern of chondroitin sulfate from articular cartilage explants in response to mechanical loading. Biochim Biophys Acta 1638: 241-248.

-Stephens, E.H., J.L. Carroll, K.J. Grande-Allen (2007) The use of collagenase III for the isolation of porcine aortic valvular interstitial cells: rationale and optimization. J Heart Valve Dis 16: $175-183$.

Taylor, P.M., S.P. Allen, S.A. Dreger, M.H. Yacoub (2002) Human cardiac valve interstitial cells in collagen sponge: a biological threedimensional matrix for tissue engineering. J Heart Valve Dis 11: 298-306; discussion 306-307.

Taylor, P., S. Allen, M. Yacoub (2000) Phenotypic and functional characterization of interstitial cells from human heart valves, pericardium and skin. J Heart Valve Dis 9: 150-158.

Throm, A., H.C. Hinds, J. Rulfs, K.L. Billiar (2005) Effects of substrate stiffness on valvular interstitial cell activation. Baltimore, Biomedical Engineering Society Annual Fall Meeting.

Walker, G.A., K.S. Masters, D.N. Shah, K.S. Anseth, L.A. Leinwand (2004) Valvular myofibroblast activation by transforming growth factor-beta: implications for pathological extracellular matrix remodeling in heart valve disease. Circ Res 95: 253-260. 